University of Nebraska - Lincoln

DigitalCommons@University of Nebraska - Lincoln

USDA National Wildlife Research Center - Staff

Publications

U.S. Department of Agriculture: Animal and Plant Health Inspection Service

November 2007

\title{
Population-Based Fish Consumption Survey and Probabilistic Methylmercury Risk Assessment
}

John J. Johnston

USDA-APHIS-Wildlife Services

Jamie L. Snow

Wyoming Department of Health

Follow this and additional works at: https://digitalcommons.unl.edu/icwdm_usdanwrc

Part of the Environmental Sciences Commons

Johnston, John J. and Snow, Jamie L., "Population-Based Fish Consumption Survey and Probabilistic Methylmercury Risk Assessment" (2007). USDA National Wildlife Research Center - Staff Publications. 703.

https://digitalcommons.unl.edu/icwdm_usdanwrc/703

This Article is brought to you for free and open access by the U.S. Department of Agriculture: Animal and Plant Health Inspection Service at DigitalCommons@University of Nebraska - Lincoln. It has been accepted for inclusion in USDA National Wildlife Research Center - Staff Publications by an authorized administrator of DigitalCommons@University of Nebraska - Lincoln. 


\title{
Population-Based Fish Consumption Survey and Probabilistic Methylmercury Risk Assessment
}

\author{
John J. Johnston ${ }^{1}$ and Jamie L. Snow ${ }^{2}$ \\ ${ }^{1}$ USDA/APHIS/WS/National Wildlife Research Center, Fort Collins, CO, USA; \\ ${ }^{2}$ Wyoming Department of Health, Cheyenne, WY, USA
}

\begin{abstract}
A fish consumption survey was developed and administered by telephone to 820 Wyoming fishing license holders. Survey respondents provided the frequency, species, and quantity of Wyoming-caught and store-bought fish consumed for license holder and household members. Deterministic and probabilistic methylmercury exposure distributions were estimated by multiplying fish consumption by speciesspecific mercury concentrations for each household member. Risk assessments were conducted for children, women of childbearing age, and the rest of the population by comparing methylmercury exposure distributions to levels of concern. The results indicate that probabilistic risk assessment likely provides a more realistic view of the risk to the study population. The results of this study clearly indicate that: (1) there is no level of fish consumption that is without risk of methylmercury exposure, (2) fish advisories may be warranted for children and women of childbearing age, and (3) that store-bought fish generally contribute more to methylmercury exposure than do Wyoming-caught fish.
\end{abstract}

Key Words: mercury, methylmercury, fish consumption, exposure, risk, probabilistic.

\section{INTRODUCTION}

Methylmercury is a toxicant found in fresh and salt water fish. A spectrum of human health effects has been observed following methylmercury exposure, with the severity depending on the sensitivity of the individual and the magnitude of the dose. For developing fetuses, infants, and children, the primary health effect of methylmercury is impaired neurological development (Rice et al. 2000). Additionally, prenatal exposure to methylmercury has been associated with blood pressure changes (Grandjean et al. 1998; Sorensen et al. 1999). Adult exposure has been associated with increased rates of cardiovascular disease (Guallar et al. 2002; Salonen et al. 1995).

Received 19 December 2006; revised manuscript accepted 2 March 2007.

Address correspondence to John J. Johnston, Chemistry Research Project Leader, USDA/APHIS/WS/National Wildlife Research Center, 4101 LaPorte Avenue, Fort Collins, CO 80521, USA. E-mail: john.j.johnston@aphis.usda.gov 
However, with respect to human nutrition, fish consumption is desirable; fish are an excellent source of high quality protein and omega-3 fatty acids, which may protect against coronary heart disease and stroke, and are thought to aid in the neurological development of unborn babies (McBride 2003). Consumers are advised to balance their fish consumption to optimize the intake of beneficial nutrients while avoiding the potentially deleterious effects of methylmercury consumption.

Health departments and/or state environmental agencies in 48 U.S. states have issued fish consumption guidelines for locally caught sport fish (USEPA 2004). Most states use the U.S. Environmental Protection Agency's (USEPA's) maximum allowable daily intake (reference dose) of methylmercury concentration to protect the health of a developing fetus $(0.1 \mu \mathrm{g} / \mathrm{kg}$ body weight $)$ when calculating fish consumption limits for women of child bearing age and children under the age of 15 years (North Carolina Dept. of Health \& Human Services 2004; USEPA 2001a; Grandjean et al. 1998; Budtz-Joergesen et al. 1999). For the general public, a number of states and countries use either $0.3 \mu \mathrm{k} / \mathrm{kg}$-day (WHO 1990), $0.4 \mu \mathrm{k} / \mathrm{kg}$-day (Stratton et al. 1987), or $0.47 \mu \mathrm{k} / \mathrm{kg}$-day (Health Canada 2001; FSA 2004; OPA 2004) as the maximum allowable daily intake and for determining fish consumption limits.

In developing fish consumption guidelines, most states combine these maximum allowable intake guidelines with average values for fish methylmercury concentrations, frequency of fish consumption, portion size, and male and female human bodyweights (US Department of Commerce 1978). Using this approach, states may issue fish specific advisories or water body specific fish consumption advisories. Fish consumption advisories are issued to advise people to limit consumption of fish with high levels of methylmercury, usually 0.4 parts per million (ppm) or greater (American Fisheries Society 2002). These advisories strive to balance the potential deleterious effects of methylmercury consumption with the nutritional benefits of fish consumption.

Basing fish advisories on mean fish methylmercury concentrations, consumption rates, bodyweights, and so on may not provide adequate protection for the entire population as subpopulations may have relevant characteristics (e.g., fish consumption patterns, sensitivity) that differ significantly from mean population values. Conversely, basing fish advisories on worst case scenarios (e.g., maximum methylmercury concentrations and consumption rates, minimum bodyweights) is overprotective and would likely deprive citizens of the beneficial aspects of fish consumption.

Therefore, we decided to use a probabilistic approach in which survey-derived fish consumption distributions were combined with species-specific fish methylmercury concentration distributions to estimate the portions of population associated with the full range of methylmercury exposures, particularly the portion of the population that exceeds maximum allowable exposure limits.

\section{OBJECTIVES}

As no fish consumption guidelines have been issued for Wyoming residents, this study was designed to: (1) evaluate fish consumption patterns of Wyoming anglers and their household members, (2) determine knowledge and attitudes about mercury exposure and fish consumption among Wyoming anglers, (3) characterize the risk of adverse health effects from methylmercury exposure for a sample of Wyoming 


\section{J. J. Johnston and J. L. Snow}

anglers and their household members, and (4) estimate the effects of limiting fish consumption with respect to methylmercury exposure. Based on the results of this study, we planned to determine the need for fish advisories in Wyoming and to propose consumption guidelines to minimize risk to Wyoming residents who consume fish.

\section{METHODS}

\section{Telephone Survey}

Fish consumption information was obtained by conducting a telephone survey of the 52,000 (out of 500,000) Wyoming residents issued fishing licenses in year 2003. Surveys were conducted between August 24 and December 14, 2005. Surveys were conducted by Wyoming Department of Health Staff and temporary employees who were supervised by Wyoming Department of Health professional employees. All telephone interviewers received instructions in both oral and written format. These instructions were based on published guidelines (Dillman 1978). These instructions included the survey questions and answers to related questions likely to be posed by the interviewees. A maximum of six attempts were made to contact individual license holders. Interviewees' answers were manually recorded onto questionnaire forms. The data from these forms were entered into a Microsoft Access (Microsoft, Redmond, WA) database by Wyoming Department of Health employees. There were far more males $(76 \%)$ than females $(24 \%)$ included in the 2003 fishing license database supplied by the Wyoming Game and Fish Department. We sought to select an equal number of males and females to ensure that we would have sufficient data to evaluate the risk for all subsets of the population. We randomly selected 1,000 male and 1,000 female license holders to participate in the study. Four hundred twenty-one females and 399 males (820 total) participated.

The survey contained a series of questions about the license holder and household member's fish consumption information (including consumption frequency, size, species, and source) for the 8 weeks prior to the survey (all information was acquired from the license holder). Fish consumption information was obtained for 2,192 individuals (license holders plus associated household members). Participants were also asked to provide some basic demographic information. If the license holder did not fish in Wyoming during year 2004, they did not qualify to participate in the study.

\section{Fish Mercury Concentration Data}

Mercury concentrations for fresh water fish were determined using data from a limited study conducted by the Wyoming Game and Fish Department in the summers of 2001 and 2002. Fish were collected from 30 Wyoming water bodies. Waters were selected for sampling based on two criteria: (1) having a fish population dominated by at least one of the USEPA recommended target species for inland freshwaters and very common in Wyoming waters and (2) considered to be a moderately to heavily utilized recreational fishery. The 98 samples analyzed by the Game and Fish 
Department were comprised of trout (71), walleye (12) catfish (6), bass (3), perch (3), kokanee salmon (2), and crappie (1).

Aliquots $(2 \mathrm{~g})$ of homogenized fish muscle were added to $10 \mathrm{~mL} \mathrm{HNO}_{3}$ and digested in a microwave bomb. Each sample was subsequently diluted to $50 \mathrm{~mL}$ with water, combined with $\mathrm{H}_{2} \mathrm{SO}_{4}(2 \mathrm{~mL}), 5 \% \mathrm{KMNO}_{4}(15 \mathrm{~mL})$, and $5 \% \mathrm{~K}_{2} \mathrm{~S}_{2} \mathrm{O}_{4}(4 \mathrm{~mL})$ and heated in a $95^{\circ} \mathrm{C}$ water bath for 2 hours. The methylmercury concentrations in the cooled digest and standard solution were quantified by cold vapor atomic absorption spectrometry using USEPA method 245.1 (USEPA 2001b; Dailey et al. 2005). Each set of nine fish samples was accompanied by high (DORM-2, NRCC, Ottawa, ON, Canada), low (NIST 2976, NIST, Gaithersburg, MD, USA) and intermediate (lab fortified duplicate fish sample) quality control samples. Mercury standards (prepared from ICP-080 Hg $1000 \mathrm{mg} / \mathrm{mL}$, Ultra Scientific, N. Kingstown, RI, USA) were included in each water bath run.

All but two samples contained methylmercury levels greater than the $0.005 \mathrm{mg} / \mathrm{kg}$ method limit of detection. The average methylmercury concentration in the Wyoming caught fish was $0.18 \mathrm{mg} / \mathrm{kg}$ with a range from less than the method limit of detection to $1.32 \mu \mathrm{g} / \mathrm{kg}$. Nine samples contained methylmercury concentrations greater than $0.40 \mathrm{ppm}$, which is the American Fish Society's fish advisory mercury concentration of concern. Of the nine mercury values greater than $0.40 \mathrm{ppm} \mathrm{Hg}$, six were from walleye, two were from channel catfish, and one from a brown trout (Wyoming Game and Fish 2002). Six of the nine samples that had mercury concentrations greater than $0.40 \mathrm{ppm}$ were from fish collected from Bighorn Reservoir in northwest Wyoming. Because the data obtained from the Game and Fish study were limited, extensive statistical evaluation of these data is restricted. Commercial fish mercury concentrations were reported by the U.S. Department of Health and Human Services (DHHS 2006). The DHHS report contains the mean, standard deviation, minimum, and maximum observed mercury concentrations for 66 varieties of commercial fish and shellfish. The same report also lists the number of samples analyzed and source of the data. Most of the reported mercury concentration data were obtained from National Marine Fisheries Service or the U.S. Food and Drug Administration.

\section{Calculating Methylmercury Exposure}

Methylmercury exposure was estimated based on species specific methylmercury data for Wyoming caught and store-bought fish for populations of concern in Wyoming: (1) women of child bearing age (15 to 44 years of age), (2) children less than 15 years of age, and (3) the remainder of the population.

For each individual (fishing license holder and each house hold member), methylmercury exposure was estimated from all fish (Wyoming caught and storebought) consumed using the following formula:

$$
\begin{array}{r}
(\text { Sum of }(\mu \mathrm{gHg} / \mathrm{gfish}) *(\mathrm{gfish} / \mathrm{serving}) *(\text { servings } / \text { month })) *(1 / \mathrm{kgBW}) * \\
(1 \mathrm{month} / 30.4 \text { days })=\mu \mathrm{gHg} /(\mathrm{kgBW} * \text { day })
\end{array}
$$

The approach used to estimate each variable in Eq. (1) differed for the deterministic and probabilistic approaches. 


\section{J. J. Johnston and J. L. Snow}

\section{Statistical Analysis}

Deterministic and probabilistic approaches were used to estimate the range of mercury exposures for the populations of interest: (1) children (<15 years), (2) women of child-bearing age ( 15 to 44 years), and (3) the remainder of the Wyoming population.

\section{Deterministic assessment}

A deterministic assessment of methylmercury exposure was conducted by using the mean and upper 90th percentile values for methylmercury content of each fish species and the mean bodyweight (based on age and sex) with the reported fish consumption habits (species, individual serving sizes, individual consumption frequencies) for each surveyed Wyoming fishing license holder and household member (Eq. [1]). The methylmercury exposure of each individual was assigned to one of the populations of interest based on the individual's sex and age. The range and frequency of methylmercury exposures for each population of interest were then determined. Analysis of these frequency distributions permitted estimation of the percentage of each sub-population that exceeded maximum allowable intake levels or any other level of concern.

\section{Probabilistic model}

A probabilistic model was developed using Crystal Ball software (Decisioneering, Denver, CO, USA) to estimate the range of mercury exposures for the populations of interest. For commercial fish, the distributions of species specific fish mercury concentrations were estimated by constructing normal distributions based on the mean and standard deviation of reported mercury fish concentration values. For each type of freshwater Wyoming fish tested by the Wyoming Game and Fish Department, a normal distribution was prepared with the reported methylmercury concentration as the mean and a standard deviation equivalent to $5 \%$ of the mean (the Quality Control criteria for the recoveries of fortified samples was $+/-10 \%)$. A custom distribution that assigned an equal probability to the mercury content for each of the analyzed fish was then prepared for each freshwater species. Age and sex-specific normal body weight distributions were also prepared using bodyweight mean and standard deviation values as reported by Burmaster and Crouch (1997).

Each iteration of the model randomly selected one of the surveyed Wyoming fishing license holders or household member. By combing this individual's reported fish consumption practices (species, serving size, and fish consumption frequency) with randomly selected values from appropriate distributions for fish mercury concentrations and sex- and age-specific bodyweight distributions, each iteration of the model estimated a possible methylmercury exposure for a Wyoming fishing license holder or household member. The range and frequency of methylmercury exposures (and associated probabilities) were estimated by running 15,000 iterations of the model for each sub-population of interest: children ( $<15$ years), women of child- bearing age (15-45 years), and the remainder of the population. Analysis of the frequency distribution for methylmercury exposure permitted estimation of the percentage of each sub-population that exceeds maximum allowable intake levels or any other level of concern. 
The effect of limiting fish consumption (serving size and/or consumption frequency) on methylmercury exposure was estimated by placing upper limits on these parameters and subsequently running the model as described earlier. To determine the effects of limiting fish species, the methylmercury concentration distributions of all species with a mean methylmercury concentration exceeding 1 ppm (swordfish, shark, tilefish, marlin) was replaced with the methylmercury concentration distribution for dark tuna.

\section{Levels of Concern}

We used the USEPA's maximum allowable daily intake (reference dose) of methylmercury concentration used to protect the health of a developing fetus $(0.1 \mu \mathrm{g} / \mathrm{kg}$ body weight $)$ as the level of concern for children and women of childbearing age (USEPA 2001a; Grandjean et al. 1997; Budtz-Joergesen et al. 1999). For the remainder of the population, we conservatively used a maximum allowable daily intake of $0.4 \mu \mathrm{g} \mathrm{Hg} / \mathrm{kg}$ body weight as the level of concern. The selection of this value was conservatively based on the knowledge that a number of states and countries use either 0.4 (Stratton et al. 1987) or 0.47 (Health Canada 2001; FSA 2004; OPA 2004) $\mu \mathrm{g} \mathrm{Hg} / \mathrm{kg}$ body weight as the maximum allowable daily intake.

\section{RESULTS}

\section{Demographics of Participants}

Eight hundred and twenty (out of 52,000) fishing license holders were randomly selected and interviewed for this study. We artificially selected $51.3 \%$ females and $48.7 \%$ males to participate in order to assure adequate representation of women of childbearing age, a high risk group for methylmercury exposure. (Table 1). Approximately $75 \%$ of the contacted license holders participated in the interview.

\section{Fish Consumption}

More than three-quarters $(83.3 \%)$ of the surveyed population consume fish for 1 to 2 months out of the year (Table 2). More than half $(62.1 \%)$ of those surveyed indicated they eat fish for 3 to 4 months annually. The most commonly consumed Wyoming fish were trout and walleye with catfish and bass being the third and fourth most commonly consumed species of fish in Wyoming, respectively. The most commonly consumed fish was store-bought white tuna (albacore). The mean consumption of white tune was greater than 1 fish meal per month. The second most commonly consumed fish was Wyoming caught trout. Mean trout consumption was 0.7 meals per month. Fresh water bass was the third most commonly consumed fish species. Surveyed households consumed both store-bought and angler-caught fresh water bass. Relative fish preferences were virtually identical for all household members. Fresh water bass consumption was followed by halibut and dark tuna. The four species with the highest maximum consumption rates (14-20 fish meals per month) were all store-bought fish. Store-bought fish constituted approximately two-thirds of all fish consumed by surveyed households (Table 3 ). Nearly $80 \%$ of the population reported consuming at least 6 ounces of fish at one sitting while 


\section{J. J. Johnston and J. L. Snow}

Table 1. Demographic composition of survey respondents.

\begin{tabular}{lrr}
\hline & \multicolumn{2}{c}{ Respondents } \\
\cline { 2 - 3 } Demographic characterization & Number & Percent \\
\hline Age & 130 & \\
18-34 & 191 & 17.2 \\
$35-44$ & 237 & 25.3 \\
$45-55$ & 197 & 31.4 \\
$>55$ & & 26.1 \\
Gender & 399 & \\
Male & 421 & 48.7 \\
Female & & 51.3 \\
Race & 765 & \\
White & 21 & 94.9 \\
Hispanic & 6 & 2.6 \\
Native American & 2 & 0.7 \\
Asian & 1 & 0.2 \\
Black & 11 & 0.1 \\
Other & & \\
Education & 21 & 2.6 \\
$\quad<12$ th grade & 269 & 33.5 \\
High school grad/GED & 17 & 2.1 \\
Trade school & 174 & 8.6 \\
Some college & 69 & 18.7 \\
Associates degree & 150 & 12.8 \\
Bachelors degree & 103 & \\
Post bachelors & & \\
\hline
\end{tabular}

only $5.7 \%$ of the population reported eating 15 ounces or more per meal (Table 4 ). The most common serving size was 6 ounces. A greater percentage of men than women consumed single serving sizes of 9 ounces. Conversely, a greater percentage of women consumed serving sizes less than 9 ounces.

Table 2. Number of months each year participants consume Wyoming caught fish.

\begin{tabular}{lccc}
\hline & \multicolumn{3}{c}{ Respondents } \\
\cline { 2 - 4 } Months/year & Number & Percent & Cumulative percent \\
\hline 0 months & 110 & 16.2 & 100.0 \\
1-2 months & 148 & 21.8 & 83.8 \\
3-4 months & 198 & 29.1 & 62.1 \\
$5-6$ months & 78 & 11.5 & 32.9 \\
$7-8$ months & 41 & 6.0 & 21.5 \\
$>8$ months & 105 & 15.4 & 15.4 \\
\hline
\end{tabular}


Fish Consumption, Methylmercury Exposure, and Risk

Table 3. Fish preference for surveyed households.

\begin{tabular}{lcrc}
\hline & \multicolumn{3}{c}{ Fish Meals Per Month } \\
\cline { 2 - 4 } & Mean & Max & 90th Percentile \\
\hline White Tuna & 1.2790 & 20 & 6 \\
Trout & 0.7042 & 6 & 1.5 \\
FW Bass & 0.3910 & 6 & 0.5 \\
Halibut & 0.2894 & 6 & 0.5 \\
Dark Tuna & 0.2894 & 20 & 0.5 \\
Walleye & 0.1889 & 6 & 0.5 \\
O. Roughy & 0.0763 & 14 & 0 \\
Sea Bass & 0.0421 & 14 & 0 \\
Snapper & 0.0391 & 6 & 0 \\
Perch & 0.0281 & 6 & 0 \\
Crappie & 0.0263 & 6 & 0 \\
Sturgeon & 0.0208 & 6 & 0 \\
Catfish & 0.0189 & 1.5 & 0 \\
Grouper & 0.0153 & 6 & 0 \\
Marlin & 0.0116 & 1.5 & 0 \\
Sunfish & 0.0110 & 6 & 0 \\
Shark & 0.0104 & 6 & 0 \\
Swordfish & 0.0061 & 0.5 & 0 \\
Whitefish & 0.0055 & 1.5 & 0 \\
Tilefish & 0.0024 & 1.5 & 0 \\
Grayling & 0.0018 & 0.5 & 0 \\
Drum & 0.0018 & 0.5 & 0 \\
Bluefish & 0.0018 & 1.5 & 0 \\
Burbot & 0.0006 & 0.5 & 0 \\
Sturgeon & 0.0000 & 0 & 0 \\
\hline & & &
\end{tabular}

\section{Consumer Awareness}

Seventy-three percent of the surveyed Wyoming fishing license holders indicated that they had heard about risks associated with eating fish. Although the survey respondents were not queried about any particular contaminant, $15 \%$ of survey respondents mentioned mercury specifically. The majority $(93 \%)$ of the surveyed population believed that fish caught in Wyoming waters are safe to very safe for consumption.

\section{Methylmercury Exposure}

Assuming that all the fish consumed by the survey respondents and their household members contained the mean methylmercury content for each species, analysis of the survey consumption data suggests that $1.6 \%$ to $10.7 \%$ of the populations of interest exceed recommended methylmercury exposure limits of $0.1 \mu \mathrm{g} / \mathrm{kg}$-day for children and women of child bearing age and $0.3 \mu \mathrm{g} / \mathrm{kg}$-day for the general population (Table 5). Conducting this analysis using the upper 90 th percentile methylmercury fish concentrations for each species consumed suggested that $6.5 \%$ to $16.7 \%$ of the populations of interest exceed recommended methylmercury exposure limits. 


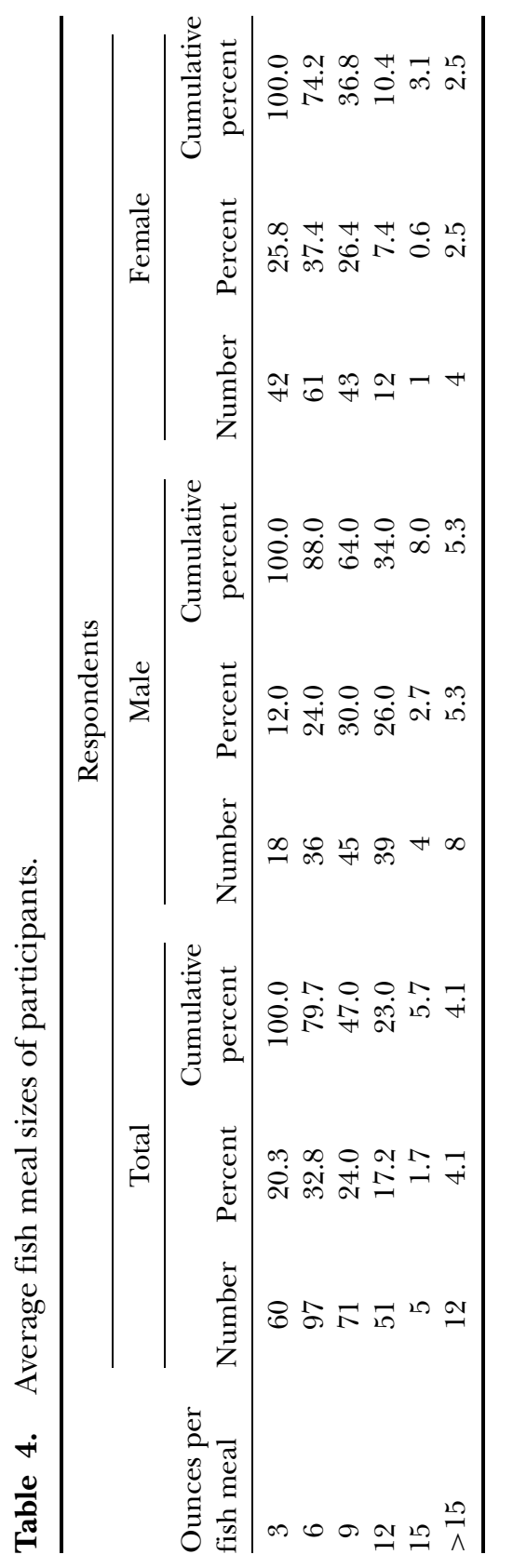


Table 5. Percentage of populations exceeding methylmercury exposure levels of concern.

\begin{tabular}{lrccc}
\hline & \multicolumn{2}{c}{ Percentage of population exceeding levels of concern } \\
\cline { 2 - 3 } \cline { 2 - 3 } Population & \multicolumn{2}{c}{ Deterministic } & & Probabilistic \\
\cline { 2 - 3 } Children $^{1}$ & 10.7 & 90 th Percentile & & Frequency Distributions \\
Women of childbearing age $^{1}$ & 7.0 & 16.7 & & 11.7 \\
Rest of population $^{2}$ & 1.6 & 6.5 & 7.9 \\
\hline
\end{tabular}

${ }^{1} 0.1 \mu \mathrm{g} / \mathrm{kg} \mathrm{BW} *$ day.

${ }^{2} 0.4 \mu \mathrm{g} / \mathrm{kg} \mathrm{BW} *$ day.

A probabilistic analysis, in which methylmercury concentrations were sampled from species specific methylmercury concentration distributions, suggested that $2.2 \%$ to $11.7 \%$ of the populations of interest exceed recommended methylmercury exposure limits. Analysis of blood mercury levels reported in the National Health and Nutrition Examination Survey (NHANES) indicated that $8 \%$ of U.S. women of childbearing age exceed the recommended methylmercury exposure limits (Schober et al. 2003). This value is virtually identical to the probabilistic analysis estimate of 7.9\%. Given the agreement of the probabilistic estimate and mercury blood level derived estimate, the probabilistic approach was used for subsequent analyses.

Limiting the frequency of fish consumption and/or serving size reduced the estimated fraction of each population of interest that exceeded recommended methylmercury exposure limits (Table 6). For example, limiting the maximum fish serving size to 2 ounces reduced the percentage of children that exceed recommended exposure limits from $11.7 \%$ to $3.9 \%$. Limiting fish consumption to four fish meals per month reduced the percentage of children that exceed recommended exposure limits to $7.3 \%$. Reducing the maximum number of fish meals to four meals per month and limiting the size of fish meals to 2 ounces reduced these values for children to $0.3 \%$ to $2.9 \%$, depending on the ratio of Wyoming-caught to store-bought fish consumed.

Further limiting methylmercury exposure by substituting dark tuna for species with high methylmercury concentrations reduced the percentage of the populations of interest that exceeded maximum exposure limits for all scenarios, which include the consumption of store-bought fish (Table 7). For children, avoiding consumption of these species that contain high methylmercury concentrations reduced the percentage of children that exceed the recommended exposure limits from $11.7 \%$ to $7.3 \%$. Further reductions are predicted if this approach is combined with limiting frequency of fish consumption and/or limiting maximum serving size.

\section{CONCLUSIONS}

Regardless of the approach used (deterministic or probabilistic), the results of this study indicated that portions of the Wyoming population likely exceed recommended methylmercury exposure limits and are at risk of adverse health effects. The probabilistic analysis indicated that $7.5 \%$ of Wyoming children and $11.7 \%$ of 


\section{J. J. Johnston and J. L. Snow}

Table 6. Effect of frequency and/or serving size consumption limitations on methylmercury exposure.

\begin{tabular}{|c|c|c|c|c|c|}
\hline & \multicolumn{2}{|c|}{$\begin{array}{l}\text { Maximum number of fish } \\
\text { meals per month }\end{array}$} & \multirow{2}{*}{$\begin{array}{l}\text { Maximum } \\
\text { serving } \\
\text { size }(\mathrm{oz})\end{array}$} & \multirow{2}{*}{$\begin{array}{c}\text { Level of } \\
\text { concern } \\
(\mu \mathrm{g} / \mathrm{kg} \mathrm{BW} \\
\text { per day })\end{array}$} & \multirow{2}{*}{$\begin{array}{c}\text { Percent of } \\
\text { population equal } \\
\text { to or exceeding } \\
\text { level of concern }\end{array}$} \\
\hline & Wyoming caught & Store bought & & & \\
\hline \multicolumn{6}{|l|}{ Children } \\
\hline & 0 & 4 & no limit & 0.1 & 7.32 \\
\hline & 0 & 4 & 2 & 0.1 & 2.89 \\
\hline & 2 & 2 & 2 & 0.1 & 2.49 \\
\hline & 4 & 0 & 2 & 0.1 & 0.32 \\
\hline & no limit & 0 & 2 & 0.1 & 0.47 \\
\hline & no limit & no limit & 2 & 0.1 & 3.88 \\
\hline \multicolumn{6}{|l|}{$\begin{array}{l}\text { Women—child } \\
\text { bearing age }\end{array}$} \\
\hline & 0 & 4 & no limit & 0.1 & 5.06 \\
\hline & 0 & 4 & 6 & 0.1 & 3.72 \\
\hline & 2 & 2 & 6 & 0.1 & 2.92 \\
\hline & 4 & 0 & 6 & 0.1 & 0.75 \\
\hline & no limit & 0 & 6 & 0.1 & 1.07 \\
\hline & no limit & no limit & 6 & 0.1 & 6.19 \\
\hline \multicolumn{6}{|l|}{$\begin{array}{l}\text { Rest of } \\
\text { population }\end{array}$} \\
\hline & 0 & 8 & no limit & 0.3 & 1.27 \\
\hline & 0 & 8 & 6 & 0.3 & 0.77 \\
\hline & 0 & no limit & 6 & 0.3 & 0.35 \\
\hline & no limit & 0 & 6 & 0.3 & 0.35 \\
\hline & no limit & 4 & 6 & 0.3 & 0.90 \\
\hline & no limit & 8 & 6 & 0.3 & 1.53 \\
\hline & no limit & no limit & 6 & 0.3 & 1.84 \\
\hline
\end{tabular}

women of childbearing age in families of fishing license holders exceed recommended methylmercury exposure limits. These findings suggest that fish advisories for Wyoming residents may be warranted.

The probabilistic model that we developed for this study permitted us to examine the potential benefits of several different approaches to limit fish consumption and subsequent methylmercury exposure for the populations of interest. The probabilistic model predictions summarized in Tables 6 and 7 indicate that all of the strategies commonly used to reduce methylmercury exposure resulting from fish consumption (limiting serving size, consumption frequency, and consumption of high mercury species) would have a desirable effect (with respect to mercury exposure) on the population of Wyoming.

Although fish advisories may appear to limit the risk of adverse effects resulting from the consumption of methylmercury-containing fish, our study indicates that it is impossible to consume fish and have no risk of methylmercury exposure. Our analysis also indicates that greater methylmercury exposure is associated with the 
Fish Consumption, Methylmercury Exposure, and Risk

Table 7. Effect of species, ${ }^{1}$ frequency, and/or serving size consumption limitations on methylmercury exposure.

\begin{tabular}{|c|c|c|c|c|c|}
\hline & \multicolumn{2}{|c|}{$\begin{array}{l}\text { Maximum number of fish } \\
\text { meals per month }\end{array}$} & \multirow{2}{*}{$\begin{array}{l}\text { Maximum } \\
\text { serving } \\
\text { size }(\mathrm{oz}) \\
\end{array}$} & \multirow{2}{*}{$\begin{array}{c}\text { Level } \\
\text { of concern } \\
(\mu \mathrm{g} / \mathrm{kg} \mathrm{BW} \\
\text { per day })\end{array}$} & \multirow{2}{*}{$\begin{array}{c}\text { Percent of } \\
\text { population equa } \\
\text { to or exceeding } \\
\text { level of concern }\end{array}$} \\
\hline & Wyoming caught & Store bought & & & \\
\hline \multicolumn{6}{|l|}{ Children } \\
\hline & 0 & 4 & no limit & 0.1 & 7.25 \\
\hline & 0 & 4 & 2 & 0.1 & 2.86 \\
\hline & 2 & 2 & 2 & 0.1 & 2.44 \\
\hline & 4 & 0 & 2 & 0.1 & 0.32 \\
\hline & no limit & 0 & 2 & 0.1 & 0.47 \\
\hline & no limit & no limit & 2 & 0.1 & 3.82 \\
\hline & no limit & no limit & no limit & 0.1 & 11.67 \\
\hline \multicolumn{6}{|l|}{$\begin{array}{l}\text { Women-child } \\
\text { bearing age }\end{array}$} \\
\hline & 0 & 4 & no limit & 0.1 & 4.91 \\
\hline & 0 & 4 & 6 & 0.1 & 3.72 \\
\hline & 2 & 2 & 6 & 0.1 & 2.82 \\
\hline & 4 & 0 & 6 & 0.1 & 0.75 \\
\hline & no limit & 0 & 6 & 0.1 & 1.07 \\
\hline & no limit & no limit & 6 & 0.1 & 6.13 \\
\hline & no limit & no limit & no limit & 0.1 & 7.85 \\
\hline \multicolumn{6}{|l|}{$\begin{array}{l}\text { Rest of } \\
\text { population }\end{array}$} \\
\hline & 0 & 8 & no limit & 0.3 & 1.08 \\
\hline & 0 & 8 & 6 & 0.3 & 0.71 \\
\hline & 0 & no limit & 6 & 0.3 & 0.77 \\
\hline & no limit & 0 & 6 & 0.3 & 0.35 \\
\hline & no limit & 4 & 6 & 0.3 & 0.69 \\
\hline & no limit & 8 & 6 & 0.3 & 1.18 \\
\hline & no limit & no limit & 6 & 0.3 & 1.76 \\
\hline & no limit & no limit & no limit & 0.3 & 2.92 \\
\hline
\end{tabular}

${ }^{1}$ Substitution of low methylmercury species (dark tuna) for species with mean methylmercury concentration exceeding $1 \mathrm{ppm}$.

consumption of store-bought fish as compared to Wyoming-caught fish. This trend suggests that the levels of methylmercury exposure noted for fishing license holders and their family members may not be significantly different from the general population. Furthermore, if families substitute Wyoming-caught fish for store-bought fish, methylmercury exposure will likely be reduced. Finally, if consumers limit their serving size, their frequency of fish consumption, and substitute low methylmercurycontaining species such as dark tuna and freshwater Wyoming fish for swordfish, shark, tilefish, and marlin, consumers can minimize methylmercury exposure while still obtaining the beneficial health aspects associated with fish consumption. Although not eliminating risk, fish advisories can provide consumers with the necessary guidance to achieve this latter scenario. These strategies are being incorporated into educational materials being developed for Wyoming citizens. 


\section{J. J. Johnston and J. L. Snow}

Our study indicates that children and women of childbearing age in households with Wyoming fishing license holders represent sub-populations of Wyoming citizens who are at greater risk of exceeding maximum allowable daily intake for methylmercury and are likely experiencing greater methylmercury-induced adverse health effects than are the rest of the Wyoming population. A fish consumption advisory targeted at Wyoming anglers, a predominantly adult male population, may fail to significantly impact these populations of greatest concern. Additionally, because the methylmercury content of store-bought fish generally exceeds that of Wyomingcaught fish, fish advisories should include recommendations for consumers of storebought fish rather than just focusing on Wyoming anglers and Wyoming-caught fish.

Finally, fish consumption surveys are often not conducted as a part of a state's strategy for developing consumption advisories. Because exposure is a key element in the estimation of risk (and permits the differentiation between risk and hazard), consumption surveys permit the accurate estimation of what level of risk exists in a population or sub-population. This can be critical information for effective and targeted risk communication and for prioritizing the allocation of limited public health resources. This article demonstrates the effectiveness of this approach and may serve as an example for other states to pursue this strategy as part of developing fish consumption advisories.

\section{ACKNOWLEDGMENTS}

We acknowledge Nicole Lindsey, Wyoming Department of Health, for her assistance in supervision of data collection and Karla Holgers for data entry. We acknowledge the Wyoming Department of Health for funding this project and the Wyoming Game and Fish Department for their support and sharing of fish residue and fishing license holder data that were crucial to the successful execution of this study. We also acknowledge the useful input of Randy Stahl, Bruce Kimball, and Richard Engeman, National Wildlife Research Center, regarding the statistical analysis.

\section{REFERENCES}

American Fisheries Society and US Environmental Protection Agency. 2002. National Forum on Contaminants in Fish Proceedings, p 16. Washington, DC, USA. October 20-22

Budtz-Jorgensen E, Keiding N, and Grandjean P. 1999. Methylmercury neurotoxicity independent of PCB exposure. Environ Health Perspect 107(5):A236-7

Burmaster DE and Crouch EAC. 1997. Lognormal distributions for body weights as a function of age for males and females in the United States, 1976-1980. Risk Anal 17:499-505

Dailey R, Raisbeck MF, Siemion R, et al. 2005. Trace metals in Wyoming fish. Bull Environ Contam Toxicol 74:1078-83

Dillman D. 1978. Mail and Telephone Surveys: The Total Design Method. John Wiley and Sons, New York, NY, USA

DHHS (US Department of Health and Human Services). 2006. Mercury levels in commercial fish and shellfish. Available at http://www.cfsan.fda.gov/ frf/sea-mehg.html

FSA (UK Food Standards Agency) 2004. Joint report of COT (Committee on Toxicity of Chemicals in Food) and SACN (Scientific Advisory Committee on Nutrition). 2004. Advice on Fish Consumption: Benefits and Risks. Norwich, UK 
Grandjean P, Weihe P, White RF, et al. 1998. Cognitive performance of children prenatal exposed to "safe" levels of methylmercury. Environ Res 77:165-72

Gualler E, Sanz-Gallardo MI, Van't Veer P, et al. 2002. Mercury, fish oils, and the risk of myocardial infarction. N Engl J Med 347:1747-54

Health Canada Advisory. 2001. Information on mercury levels: Mercury exposure and Health Canada guidelines. Available at http://www.hc-sc.gc.ca/ahc-asc/media/advisories-avis /2001/2001_60_e.html

McBride D. 2003. Statewide Bass Advisory. Washington State Department of Health, Olympia, WA, USA

North Carolina Dept. of Health \& Human Services. 2004. North Carolina Fish Eating Guidelines. Raleigh, NC, USA

OPA (Ontario Public Health Association). 2004. Position on Fish Consumption with Respect to Methylmercury Content by Pregnant Women, Women of Childbearing Age, and Young Children. Toronto, ON, Canada

Rice G, Swartout J, Mahaffey K, et al. 2000. Derivation of US EPA's oral Reference Dose (RfD) for methylmercury. Drug Chem Toxicol. Feb:23(1):41-54

Salonen JT, Seppanen K, Nyyssonen K, et al. 1995. Intake of mercury from fish, lipid peroxidation and the risk of myocardial infarction and coronary, cardiovascular and death in eastern Finnish men. Circulation 91:645-55

Schrober S, Sinks T, Jones R, et al. 2003. Blood mercury levels in US children and women of childbearing age, 1999-2000. JAMA 289 (13):1667-74

Sorensen N, Murata K, Budtz-Jorgensen E, et al. 1999. Prenatal methylmercury exposure as a cardiovascular risk factor at seven years of age. Epidemiology 10:370-5

Stratton JW, Smith DF, Fan AM, et al.1987. Methylmercury in Northern Coastal Mountain Lakes: Guidelines for Sport Fish Consumption for Clear Lake (Lake County), Lake Berryessa (Napa County) and Lake Herman (Solano country). California Department of Health Services, Berkeley, CA, USA

US Department of Commerce. 1978. Report on the Chance of U.S. Seafood Consumers Exceeding Currently Acceptable Daily Intake for Mercury and Recommended Controls. Washington, DC, USA

USEPA (US Environmental Protection Agency). 2001a. Integrated Risk Information System: Methylmercury. Available at http://www.epa.gov/iris/

USEPA. 2001b. Mercury in Water by Manual Cold Vapor Atomic Absorption (CVAA) EPA Method 245.1. Available at http://www.epa.gov/region09/qa/pdfs/245_1dqi.pdf

USEPA. 2004. National Listing of Fish Advisories. EPA-823-F-04-016. Office of Water, Washington, DC, USA

WHO (World Health Organization). 1990. Methylmercury Criteria Document 101. Available at http://www.inchem.org/documents/ehc/ehc/ehc101.htm

Wyoming Game, Fish Department. 2002. Mercury and Selenium in Fish: Results of a Baseline Survey in Wyoming. Cheyenne, WY, USA 
Copyright of Human \& Ecological Risk Assessment is the property of Taylor \& Francis Ltd and its content may not be copied or emailed to multiple sites or posted to a listserv without the copyright holder's express written permission. However, users may print, download, or email articles for individual use. 